\title{
Animal Care and Service Workers
}

National Cancer Institute

\section{Source}

National Cancer Institute. Animal Care and Service Workers. NCI Thesaurus. Code C122423.

Workers who provide care for animals. They feed, water, groom, bathe, and exercise pets and other nonfarm animals. Job tasks vary by position and place of work. 